\title{
River catchment rainfall series analysis using additive Holt-Winters method
}

\author{
Yan Jun Puah ${ }^{1, *}$, Yuk Feng Huang ${ }^{1}$, Kuan Chin Chua ${ }^{1}$ and Teang Shui Lee ${ }^{2}$ \\ ${ }^{1}$ Department of Civil Engineering, Universiti Tunku Abdul Rahman, Jalan Genting Klang, Setapak, \\ 53300 Kuala Lumpur, Malaysia. \\ ${ }^{2}$ Faculty of Engineering, Universiti Putra Malaysia, Selangor, Malaysia. \\ ${ }^{*}$ Corresponding author.e-mail: pyanjun421@gmail.com
}

Climate change is receiving more attention from researchers as the frequency of occurrence of severe natural disasters is getting higher. Tropical countries like Malaysia have no distinct four seasons; rainfall has become the popular parameter to assess climate change. Conventional ways that determine rainfall trends can only provide a general result in single direction for the whole study period. In this study, rainfall series were modelled using additive Holt-Winters method to examine the rainfall pattern in Langat River Basin, Malaysia. Nine homogeneous series of more than 25 years data and less than 10\% missing data were selected. Goodness of fit of the forecasted models was measured. It was found that seasonal rainfall model forecasts are generally better than the monthly rainfall model forecasts. Three stations in the western region exhibited increasing trend. Rainfall in southern region showed fluctuation. Increasing trends were discovered at stations in the south-eastern region except the seasonal analysis at station 45253. Decreasing trend was found at station 2818110 in the east, while increasing trend was shown at station 44320 that represents the north-eastern region. The accuracies of both rainfall model forecasts were tested using the recorded data of years 2010-2012. Most of the forecasts are acceptable.

\section{Introduction}

Climate change as a global issue has received concerns from many researchers in the world. Many serious large-scale natural disasters occurred all around the world in the recent years. Particularly in 2013, cyclones, storms, hurricanes, earthquake as well as drought and flood in Philippines, India, the United States, Mexico, China, southern and western Africa and also southern Asia displaced millions of people. Thus, climate change is definitely a noteworthy issue to be studied. Cyclones, storms and hurricanes bring heavy precipitation which can cause flooding of inland. Thus, analysing precipitation trends is one of the assessment tools of climate change, especially in tropical countries which have no distinct four seasons. Study on precipitation has received attention in many countries such as Spain, Italy, Ethiopia, Nigeria, India, Malaysia, South Korea, Australia and so on (Luís et al. 2000; Seleshi and Zanke 2004; Chang and Kwon 2007; Guhathakurta and Rajeevan 2008; Wong et al. 2009; Obot et al. 2010; Caloiero et al. 2011; Kamruzzaman et al. 2011) over the past few decades. It not only focusses in the assessment of climatic change, but also in managing agricultural issues as well as water resources.

The commonly used method in analyzing rainfall trend is the non-parametric rank-based Mann-Kendall test. Chang and Kwon (2007) used Mann-Kendall test to investigate the spatial variations of trends in summer precipitation amount,

Keywords. Additive Holt-Winters; monthly rainfall series; seasonal rainfall series; climate change; Langat River Basin. 
rain intensity and also heavy precipitation. Seleshi and Zanke (2004), determined changes in both rainfall amount and rainy days with Mann-Kendall test on six indices and evaluated the slopes of the trends using least-squares linear fitting. Wang et al. (2013) observed insignificant increasing trend in seasonal (except autumn) and annual precipitation in Jinsha River Basin in China by Mann-Kendall test. A short-period rainfall trend study was done for the whole territory of Nigeria (Obot et al. 2010). Since the presence of serial correlation will alter the probability of rejecting the null hypothesis, prewhitening process was performed. Only one out of six geopolitical zones showed significant trend from Mann-Kendall test during the 30-year study period. Instead of pre-whitening the time series, the Mann-Kendall test was modified by correcting the underestimated variance for positively autocorrelated data in a case study of rainfall trend analysis in India (Mondal et al. 2012). Sen's slope estimator was used to predict the magnitude of the trend. Another analysis of precipitation trends was done to detect trends of annual and seasonal rainfall in Calabria, Italy (Caloiero et al. 2011). The pre-whitening approach of von Storch's procedure was first applied before trend detection analysis of Mann-Kendall test. More negative trends showed in each season except summer.

Both Mann-Kendall test and cumulative sum (CUSUM) test were used in some studies for rainfall trend analysis (Karpozos et al. 2010; Afzal et al. 2011). CUSUM test detects sudden shift in trend. Sequential Mann-Kendall test is employed to see the change in trend with time. Karpozos et al. (2010) studied precipitation trend analysis in Pieria Region (Aison river basin with an area of $1232 \mathrm{~km}^{2}$ ), Greece. A general negative trend was observed in the whole region due to the decreasing trend during autumn, winter and spring. Also, apparent decrease in annual precipitation was shown in all stations during 1987-1993 from the sequential Mann-Kendall test.

Another non-parametric rank-based test which is used in trend analysis is Spearman's rho test. Wong et al. (2009) had analyzed the variability of rainfall for peninsular Malaysia and found that the only significant trends were found in the west coast region with increasing trend in November, the northeast monsoon and annual rainfall. Jayawardene et al. (2005) used Spearman's rho test to confirm the results from Mann-Kendall test in a study of rainfall trend in Sri Lanka. The authors concluded that Mann-Kendall test and Spearman's rho test have similar power in detecting trends. Least-square regression method was also used in this study and it revealed that the computed trend values are higher from 1949 onwards and most of them were negative. Miller and Piechota (2008) investigated trend of hydroclimatic variables around the Colorado River Basin using Mann-Kendall test, Spearman's rho test and linear regression statistical test. It was found that only 17 climate divisions showed increasing rainfall during February and others remained unchanged over the Colorado River Basin. In a study of Tabari et al. (2012), the standardized precipitation index was evaluated to quantify the degree of wetness to examine the spatial characteristics of drought. Both Spearman's test and Kendall's test were used to determine the temporal rainfall trends and the magnitude was found using Theil-Sen's estimator. More negative trends were found in the annual rainfall and all seasonal rainfalls.

Besides non-parametric method, there were also other methods used for studying rainfall trends. Guhathakurta and Rajeevan (2008) have studied the trends in rainfall pattern over whole India using 'low-pass filter' on linear fit, and there were no linear trend found in both the monsoon season rainfall and the four monsoon months for whole India. Ghahraman and Taghvaeian (2008) also investigated annual rainfall trend in Iran for the period of equal or less than 50 years using regression line method. The study period was further broken down into last 40 years and last 30 years to observe the recent change in rainfall. It was discovered that the result of increasing or decreasing trends found might not reflect the true scenario since it depends on the length of the study period.

Luís et al. (2000) commented that trends in climatic series are rarely linear even though linear regression method is a popular way to assess relationships between two variables. Besides, linear regression assumes normality and homogeneity of variance throughout the series, which is hardly achieved by rainfall time series. Thus, nonparametric method would be a better approach since it is less affected by outliers and does not require normality assumption. However, results found from these methods are in single direction (either increasing or decreasing) and mostly statistically insignificant.

Only a few hydrological studies on time series trend analyses were done using Holt-Winters method. Non-stationarity in precipitation and temperature in the Murray Darling Basin was investigated to provide significant evidence of climate change (Kamruzzaman et al. 2011). Two analyses were applied to monthly rainfall and average maximum temperature time series in ten selected stations. Two seasonal variations, the pacific decadal oscillation (PDO) and the southern oscillation index (SOI) were taken into account in the multiple regression models for rainfall and temperature. The residuals from the regression which represented the random variation about the fitted 
values were first investigated. Then, the CUSUM technique was also applied to the residuals and evidence of non-stationarity in both temperature and rainfall was discovered. Next, Additive HoltWinters method was adopted since it allowed the underlying mean, trend and seasonal components to change over time. Thus, this method was used to track shifts in the parameters of a time series. It was revealed that reduction in rainfall was accompanied by negative SOI but there was no trend found in both PDO and SOI series. Furthermore, in Holt-Winters analysis, negative trend was found in agreement with the previous analysis.

Gundalia and Dholakia (2012) used additive Holt-Winters method for prediction of maximum and minimum temperatures in Junagadh Region in India. Only maximum and minimum daily temperatures from June to October were concerned. The optimal smoothing parameter $\alpha, \beta$ and $\gamma$ were chosen by minimizing the value of mean absolute deviation (MAD). The accuracy of the forecasted models was measured by MAD, mean square error (MSE) and mean absolute percentage error (MAPE). It was found that the models fit well within the acceptable limits. Also, only 3 out of 153 observations of MAPE are found greater than 10 in maximum temperature time series, which indicates that such time series exhibit less fluctuations and gave better result as compared to minimum temperature time series.

The Holt-Winters model can be used in forecasting. A study of forecasting rainfall in Nakhon Ratchasima Province, Thailand was done by Sopipan (2014). Both ARIMA (auto regressive integrated moving average) and multiplicative Holt-Winters method were used to forecast month ly rainfall at 15 stations with historical monthly data from April 2005 to March 2013. The MAPE, MSE and mean absolute error (MAE) were used to measure the performance. Forecasts from both methods were found to be acceptable but ARIMA gave a better result for that case.

Holt-Winters method is an exponential smoothing method, which was initially used for forecasting sales for inventory control. There are few advantages of the exponentially weighed moving average: the decreasing weight on historical data, the simplicity of the method and requirement of less data. Holt (2004) extended the exponential weighed moving averages to allow trend and seasonal variation. Winters (1960) concluded that this exponential forecasting model not only provides better forecasting compared to some other forecasting methods, it also reacts more efficiently when there is a sudden shift in the time series. Since the Holt-Winters method decomposes the time series to level, trend and seasonal components, trend of the rainfall time series can be found without the effect of seasonal variation on rainfall. Most methods used in rainfall trend analysis are only capable in finding trends in single direction, while additive Holt-Winters method can provide a better picture of the trend movement for the study period, which makes additive Holt-Winters method more useful in studying rainfall trends.

Model performance evaluation is an important step of model development and calibration process. The Nash-Sutcliffe efficiency measure (NSE) is commonly used in evaluating performance of rainfall-runoff model. Krause et al. (2005) compared a few efficiency criteria, such as NSE, coefficient of determination and index of agreement, which are usually used in hydrologic modelling studies. It was stated that the greatest drawback of the NSE is that the differences between the observed and forecasted values are calculated as squared values, which will eventually overemphasize a large value (Criss and Winston 2008). Besides, as the mean observed value is used as a standard, it can either be a very poor predictor, where the observed data has strong seasonal variation, or a good predictor, for time series that has small variation around a relatively constant mean value (Schaefli and Gupta 2007).

This study aims to determine the monthly and seasonal rainfall trends specifically within the Langat River Basin for the 10 selected rainfall stations using the additive Holt-Winters method. The study period is from 1971 to 2012 depending on the availability of data. Outcomes from this study is envisaged to be used as reference for assessment of climate change and also projecting future rainfall trends for water resources management and planning in Langat River Basin, Malaysia.

\section{Materials and methods}

\subsection{Study Area}

The Langat River Basin located at the central west of Peninsular Malaysia, occupies the whole southern region of the State of Selangor and part of the northern region of the State of Negeri Sembilan. It lies between latitudes $2^{\circ} 45^{\prime}-3^{\circ} 20^{\prime} \mathrm{N}$ and longitudes $101^{\circ} 20^{\prime}-102^{\circ} 0^{\prime} \mathrm{E}$ with an area of $2200 \mathrm{~km}^{2}$, approximately. There are three tributaries that drain through the Langat River Basin; the Langat River, the Semenyih River and the Labu River. The main tributary, the Langat River, originates from the western slope of Titiwangsa Range, which is the main range dividing peninsular Malaysia right through in the middle, and flows southwestern into Malacca Strait.

The Langat River Basin is the major area for economic growth since Putrajaya City, the Federal 
Administrative Centre of Malaysia, and the Multimedia Super Corridor that covers Cyberjaya and KLIA (Kuala Lumpur International Airport), are located within this area. Two reservoirs, which are the Semenyih Reservoir and the Hulu Langat Reservoir, and eight water treatment plants, are in the river basin. These water sources supply water to two-third of the Selangor State, and provides freshwater to approximately 1.2 million people within the river basin. However, rapid development in the southern region of Selangor State, especially the District of Hulu Langat, District of Sepang, as well as, Kuala Langat is expected to be continued in the near future with commencement of hitech-based industrial operations and other forms of manufacturing activities along with the development of new urban centres. Thus, substantial increase in water demand is expected. Rapid developments will inevitably lead to a great change of the quantity, as well as, quality of water resources in a river basin. Developments in Putrajaya and Cyberjaya have driven the urbanization and industralization in the Langat River Basin. Changes in rainfall pattern could therefore be more obvious in this river basin compared to other river basins in the country.

The climate of Langat River Basin is equatorialmonsoon with high but uniform annual temperatures and high humidity. Generally, the seasons in this area can be categorized by monsoon and inter-monsoon seasons, which are southwest monsoon (May-August), inter-monsoon (SeptemberOctober and March-April) and northeast monsoon (November-February of the following year).

\subsection{Data collection and data checking}

Historical rainfall data utilized in the present study were collected from the Department of Irrigation and Drainage (DID), Malaysia and the Malaysian Meteorological Department (MMD). Hourly and daily rainfalls were obtained and used to sum up the monthly and seasonal data. In order to investigate the rainfall trend effectively, rainfall time series of more than 25 years of duration have been used. Besides, rainfall time series of more than $10 \%$ missing data were also eliminated in this study to achieve higher accuracy of analysis. Therefore, only time series of 4 stations from DID and 6 stations from MMD spanning the period of 1971-2012 were used to investigate the changes in rainfall pattern. All utilized stations' name and code, the coordinate of the stations and the period of analysis are given in table 1 . Figure 1 shows locations of the 10 stations, which are located in the Langat River Basin.

The detection of missing value was the first step of data checking. Data with less than $10 \%$ of missing values was then repaired by using the Inverse Distance Weighted (IDW) interpolation method.

Generally, rainfall data used in the studies of rainfall trends should only be affected by weather and climate. However, other factors like location of the station, station environment, observing practices and instruments will also influence the homogeneity of rainfall time series. Thus, homogeneity tests of rainfall data were carried out before further investigations followed. Since maximum and median of the rainfall series generally exhibit lower variability than annual rainfall, inhomogeneities are easier to be detected in these variables. Thus, four homogeneity tests were applied to annual median and maximum rainfall, namely the Alexandersson standard normal homogeneity test (SNHT), the Buishand range test, the Pettitt test and the von Neumann ratio test (Wijingaard et al. 2003). The null hypotheses for these four tests are the same, indicating the annual values $Y_{i}$ of the testing variable $Y$ are independent and identically distributed. The alternative hypothesis of SNHT, the Buishand range test and the Pettitt test is defined as a step-wise shift in the mean, a break, in the time series is present. These three tests are location-specific tests, which are useful in detecting the year where a break probably exists. Under the alternative hypothesis of the fourth test, the

Table 1. List of station code, name, study period, latitude and longitude.

\begin{tabular}{|c|c|c|c|c|c|}
\hline Station code & Station name & Study period & Duration & Longitude & Latitude \\
\hline 2815001 & Pejabat JPS Sg Mangg & 1970-2012 & 43 years & $101^{\circ} 32^{\prime} \mathrm{E}$ & $2^{\circ} 49^{\prime} \mathrm{N}$ \\
\hline 2818110 & SMK Bdr Tasik Kesuma & $1972-2012$ & 41 years & $101^{\circ} 52^{\prime} \mathrm{E}$ & $2^{\circ} 53^{\prime} \mathrm{N}$ \\
\hline 2913001 & P/KWLN P/S Telok Gong & $1974-2012$ & 38 years & $101^{\circ} 23^{\prime} \mathrm{E}$ & $2^{\circ} 55^{\prime} \mathrm{N}$ \\
\hline 2917001 & RTM Kajang & $1976-2012$ & 36 years & $101^{\circ} 47^{\prime} \mathrm{E}$ & $2^{\circ} 59^{\prime} \mathrm{N}$ \\
\hline 44239 & Sepang Estate & $1975-2012$ & 37 years & $101^{\circ} 43^{\prime} \mathrm{E}$ & $2^{\circ} 41^{\prime} \mathrm{N}$ \\
\hline 44255 & Pusat Pertanian Teluk Datuk & $1984-2012$ & 29 years & $101^{\circ} 31^{\prime} \mathrm{E}$ & $2^{\circ} 49^{\prime} \mathrm{N}$ \\
\hline 44256 & Banting Oil Palm Research Station & $1981-2012$ & 32 years & $101^{\circ} 30^{\prime} \mathrm{E}$ & $2^{\circ} 49^{\prime} \mathrm{N}$ \\
\hline 44320 & Ampangan Ulu Langat & $1984-2012$ & 29 years & $101^{\circ} 52^{\prime} \mathrm{E}$ & $3^{\circ} 13^{\prime} \mathrm{N}$ \\
\hline 45253 & New Labu Estate & $1984-2012$ & 29 years & $101^{\circ} 48^{\prime} \mathrm{E}$ & $2^{\circ} 47^{\prime} \mathrm{N}$ \\
\hline 45254 & Kirby Estate & 1984-2012 & 29 years & $101^{\circ} 51^{\prime} \mathrm{E}$ & $2^{\circ} 45^{\prime} \mathrm{N}$ \\
\hline
\end{tabular}




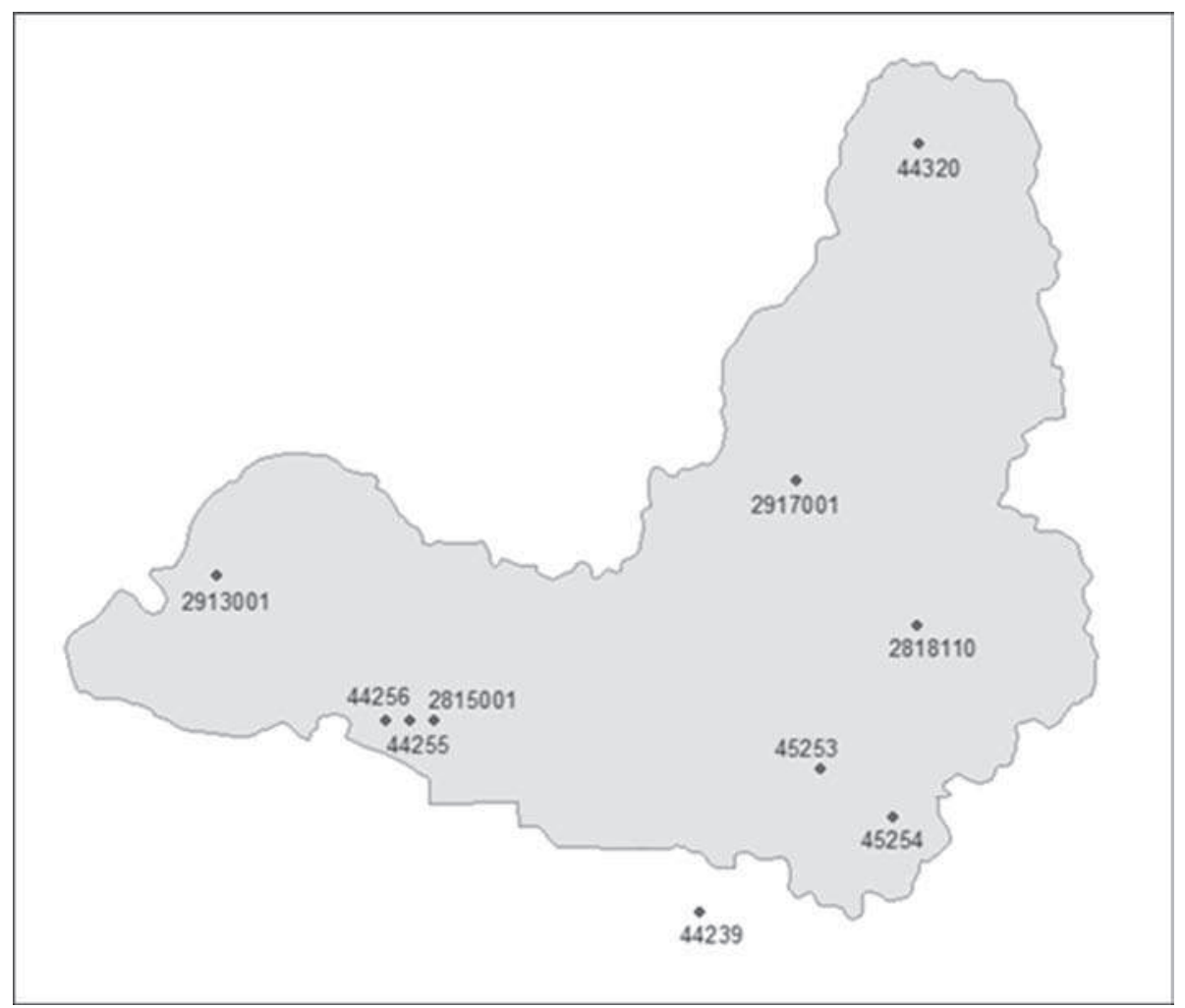

Figure 1. Locations of the selected 10 stations in Langat River Basin.

von Neumann ratio test assumes the series tested was not randomly distributed.

The criteria proposed by Wijingaard et al. (2003) were adopted in this study. The time series is categorized as 'suspect' when at least three out of the suggested four tests reject the homogeneity. If two tests reject the homogeneity, then the time series is known to be 'doubtful'. The time series is 'useful' if only one or none of the tests rejects the homogeneity.

\subsection{The Holt-Winters method}

Instead of determining whether the monthly and seasonal rainfall series is increasing or decreasing, modelling rainfall series was proposed in this paper to find the rainfall pattern for each station during the study period. Holt (2004) extended the exponential weighed moving averages for series with no trend, or additive (linear) or multiplicative (non-linear) trend and non-seasonal series, or series with seasonal variation in additive or multiplicative patterns.

In this study, model chosen for rainfall series is the additive Holt-Winters method, which exhibits a linear trend and has a constant (additive) seasonal variation. The forecast is composed by level $\left(L_{t}\right)$, trend $\left(b_{t}\right)$ and seasonal variation $\left(s_{t}\right)$, and the estimate of level, trend and seasonal variation at time $t$ are computed using the following equations:
Level:

$$
L_{t}=\alpha\left(Y_{t}-s_{t-c}\right)+(1-\alpha)\left(L_{t-1}+b_{t-1}\right) .
$$

Trend:

$$
b_{t}=\beta\left(L_{t}-L_{t-1}\right)+(1-\beta) b_{t-1} .
$$

Seasonal:

$$
\begin{gathered}
s_{t}=\gamma\left(Y_{t}-L_{t}\right)+(1-\gamma) s_{t-c}, \\
F_{t+m}=L_{t}+b_{t} m+s_{t-c+m}
\end{gathered}
$$

where $Y_{t}$ is the recorded monthly or seasonal rainfall, $L_{t-1}$ and $b_{t-1}$ are the estimate of level and trend at time $t-1$, respectively, while $s_{t-c}$ is the estimate of seasonal factor in time $t-c$, where $c$ represents the number of periods in a year $(c=12$ for monthly data, $c=4$ for quarterly data). $F_{t+m}$ denotes the forecasted value at time $t$ with $m$ periods ahead. The smoothing parameters, $\alpha, \beta$ and $\gamma$, are the weights (values between 0 and 1 ) of historical values and are selected by minimizing the value of MSE over observations. This step would be done by using the R-programme. All parameters obtained were listed in table 2 .

In equation (1), the estimate of the level at time $t$ is adjusted for the trend of the previous period. The estimated value of trend of the previous period, $b_{t-1}$, is added to the last smoothing value, $L_{t-1}$, to 
eliminate lag and bring $L_{t}$ to the approximate level of the current data value. The smoothing parameter $\alpha$ controls the estimate of level with weighing the most recent observations with a weight value of $\alpha$ and the most recent forecast value with a weight of $(1-\alpha)$ for smoothing purpose. Since there is a trend in the time series, the next value will be either higher or lower than the current one. Then, the estimate of trend in equation (2) is expressed as the difference between last two smoothed values of level. Since randomness might exist, the smoothing parameter $\beta$ is multiplied to the trend in the last period $\left(L_{t}-L_{t-1}\right)$, while the previous estimated value of trend is multiplied by $(1-\beta)$. Therefore, the Holt's algorithm can react efficiently when there is a sudden shift in time series.

The initialization process for the Holt's algorithm requires three estimates for first smoothed value for level $\left(L_{1}\right)$, trend $\left(b_{1}\right)$ and seasonal variation $\left(s_{1}\right)$ :

Level:

$$
L_{c}=\frac{1}{c}\left(Y_{1}+Y_{2}+\cdots+Y_{c}\right)
$$

Trend:

$$
b_{s}=\frac{1}{c}\left(\frac{Y_{c+1}-Y_{1}}{c}+\frac{Y_{c+2}-Y_{2}}{c}+\cdots+\frac{Y_{c+c}-Y_{c}}{c}\right) \text {. }
$$

Seasonal:

$$
s_{1}=Y_{1}-L_{c}, s_{2}=Y_{2}-L_{c}, \ldots, s_{c}=Y_{c}-L_{c} .
$$

Both monthly and seasonal rainfall series were investigated in this study. Since the rainy season

Table 2. Holt-Winters parameter values obtained from $R$-program.

\begin{tabular}{llccc}
\hline Station code & & $\alpha$ & $\beta$ & $\gamma$ \\
\hline 44239 & Monthly & 0.02 & 0.03 & 0.18 \\
\multirow{4}{*}{44255} & Seasonal & 0.02 & 0.18 & 0.19 \\
\multirow{4}{*}{44256} & Monthly & 0.03 & 0.06 & 0.20 \\
& Seasonal & 0.09 & 0.18 & 0.13 \\
44320 & Monthly & 0.12 & 0.01 & 0.12 \\
45253 & Seasonal & 0.21 & 0.04 & 0.11 \\
& Monthly & 0.04 & 0.03 & 0.25 \\
45254 & Seasonal & 0.05 & 0.16 & 0.28 \\
\multirow{2}{*}{2815001} & Monthly & 0.01 & 0.02 & 0.24 \\
\multirow{2}{*}{2818110} & Seasonal & 0.22 & 0.08 & 0.25 \\
& Monthly & 0.12 & 0.01 & 0.18 \\
2913001 & Seasonal & 0.21 & 0.02 & 0.07 \\
& Monthly & 0.10 & 0.02 & 0.15 \\
& Seasonal & 0.23 & 0.07 & 0.13 \\
& Monthly & 0.10 & 0.03 & 0.12 \\
& Seasonal & 0.21 & 0.09 & 0.14 \\
& Monthly & 0.03 & 0.01 & 0.17 \\
& Seasonal & 0.15 & 0.06 & 0.10 \\
\hline
\end{tabular}

is concentrated in few specific consecutive months but not the particular months, seasonal rainfall series might provide a better picture of the rainfall trend for the study period. The four seasons are southwest monsoon (SWM, from May to August), northeast monsoon (NEM, from November to February of the following year) and two inter-monsoons (ITM1 and ITM2, from March to April and September to October, respectively).

\subsection{Model performance}

Goodness-of-fit is the measure of the accuracy of the forecasted model to actual value. Three standard error measures, namely mean square error (MSE), mean absolute percentage error (MAPE) and mean absolute deviation (MAD) of the forecasted model throughout the whole study period were calculated to examine the fitting of the model. For all three measures, the smaller the value, the better the forecast accuracy. $Y_{t}$ and $\widehat{Y}_{t}$ denote the actual data and forecasted value, respectively, while $n$ is the number of observations. Other than that, in order to measure the power of forecasting for Holt-Winters method, rainfall data of year 2012 were assumed to be unknown. After forecasting rainfall of year 2012, recorded data were then used to measure the error between forecasted value and the recorded value.

\subsubsection{Mean square error (MSE)}

Mean square error (MSE) is the average value of the squared individual errors; this is a commonly used measurement of difference between forecasted value and actual data. However, due to the squared error term, the value of MSE will be magnified and result in misleading conclusion.

$$
\mathrm{MSE}=\frac{\sum_{t=1}^{n}\left(Y_{t}-\hat{Y}_{t}\right)^{2}}{n} .
$$

\subsubsection{Mean absolute percentage error (MAPE)}

Mean absolute percentage error (MAPE) is a better error measurement since it does not magnify

Table 3. A scale of judgement of forecast accuracy.

\begin{tabular}{ll}
\hline MAPE & \multicolumn{1}{c}{$\begin{array}{c}\text { Judgement of } \\
\text { forecast accuracy }\end{array}$} \\
\hline Less than $10 \%$ & $\begin{array}{l}\text { Highly accurate } \\
\text { Good forecast }\end{array}$ \\
$11 \%-20 \%$ & Reasonable forecast \\
$51 \%-50 \%$ & Inaccurate forecast \\
\hline
\end{tabular}


large errors as MSE does. However, the downside of this measurement is that MAPE will go to extreme when the actual data is small (close to zero) as the denominator is the actual data.
Lewis (1982) had developed a scale to judge the accuracy of the forecasted model using MAPE, as shown in table 3.

\subsubsection{Mean absolute deviation (MAD)}

$\mathrm{MAPE}=\frac{\sum_{t=1}^{n}\left|\frac{Y_{t}-\hat{Y}_{t}}{Y_{t}}\right|}{n}$.

Mean absolute deviation (MAD) is the average of the absolute value of error terms regardless

Table 4. Result of homogeneity tests at each station.

\begin{tabular}{|c|c|c|c|c|c|c|c|}
\hline \multirow{2}{*}{$\begin{array}{l}\text { Station } \\
\text { code }\end{array}$} & \multirow{2}{*}{$\begin{array}{c}\text { Study } \\
\text { period }(n)\end{array}$} & \multirow{2}{*}{$\begin{array}{l}\text { Critical } \\
\text { value }\end{array}$} & \multirow[b]{2}{*}{ Test } & \multicolumn{2}{|c|}{ Monthly series } & \multicolumn{2}{|c|}{ Seasonal series } \\
\hline & & & & Median & Max & Median & $\operatorname{Max}$ \\
\hline \multirow[t]{4}{*}{2815001} & \multirow[t]{4}{*}{43} & 8.205 & SHNT & 1.738 & 3.811 & 4.074 & 1.62 \\
\hline & & 1.536 & $\mathrm{BR}$ & 1.01 & 1.212 & 1.113 & 0.906 \\
\hline & & 187.4 & Pettitt & 106 & 146 & 94 & 96 \\
\hline & & 1.505 & VNR & $1.957^{*}$ & 1.439 & $2.068^{*}$ & $1.904^{*}$ \\
\hline \multirow[t]{4}{*}{2818110} & \multirow[t]{4}{*}{41} & 8.135 & SHNT & 6.6 & 6.906 & 5.058 & 6.718 \\
\hline & & 1.532 & $\mathrm{BR}$ & 1.492 & 1.095 & $1.55^{*}$ & 1.119 \\
\hline & & 173.8 & Pettitt & 150 & 162 & 136 & 124 \\
\hline & & 1.495 & VNR & 1.458 & $2.026^{*}$ & $1.642^{*}$ & $1.817^{*}$ \\
\hline \multirow[t]{4}{*}{2913001} & \multirow[t]{4}{*}{39} & 8.055 & SHNT & 4.731 & 0.92 & 4.3 & 1.19 \\
\hline & & 1.527 & $\mathrm{BR}$ & 1.111 & 0.688 & 1.258 & 0.985 \\
\hline & & 161 & Pettitt & 76 & 86 & 100 & 82 \\
\hline & & 1.483 & VNR & 1.449 & $2.568^{*}$ & $1.9^{*}$ & $2.202^{*}$ \\
\hline \multirow[t]{4}{*}{2917001} & \multirow[t]{4}{*}{37} & 7.965 & SHNT & $9.212^{*}$ & 5.557 & $9.955^{*}$ & $8.495^{*}$ \\
\hline & & 1.521 & $\mathrm{BR}$ & 1.504 & 1.228 & $1.572^{*}$ & $1.564^{*}$ \\
\hline & & 149 & Pettitt & $204^{*}$ & $152^{*}$ & $212^{*}$ & $196^{*}$ \\
\hline & & 1.469 & VNR & 1.455 & $1.674^{*}$ & $1.503^{*}$ & $1.501^{*}$ \\
\hline \multirow[t]{4}{*}{44239} & \multirow[t]{4}{*}{38} & 8.01 & SHNT & 3.446 & 2.199 & 2.779 & 2.669 \\
\hline & & 1.524 & BR & 0.846 & 0.935 & 0.754 & 1.23 \\
\hline & & 155 & Pettitt & 105 & 97 & 68 & 108 \\
\hline & & 1.476 & VNR & $1.975^{*}$ & $1.925^{*}$ & $2.346^{*}$ & $2.045^{*}$ \\
\hline \multirow[t]{4}{*}{44255} & \multirow[t]{4}{*}{29} & 7.58 & SHNT & 7.474 & $9.805^{*}$ & $7.583^{*}$ & 4.863 \\
\hline & & 1.493 & $\mathrm{BR}$ & $1.58^{*}$ & $1.513^{*}$ & $1.502^{*}$ & 1.188 \\
\hline & & 102 & Pettitt & $124^{*}$ & $110^{*}$ & 102 & 84 \\
\hline & & 1.408 & VNR & 1.357 & $1.443^{*}$ & $1.676^{*}$ & $2.293^{*}$ \\
\hline \multirow[t]{4}{*}{44256} & \multirow[t]{4}{*}{32} & 7.74 & SHNT & $11.765^{*}$ & $8.892^{*}$ & $10.979^{*}$ & 5.929 \\
\hline & & 1.506 & $\mathrm{BR}$ & 1.373 & 0.831 & 1.109 & 0.911 \\
\hline & & 119 & Pettitt & 84 & 109 & 91 & 58 \\
\hline & & 1.434 & VNR & 1.168 & $1.663^{*}$ & $1.694^{*}$ & $2.19^{*}$ \\
\hline \multirow[t]{4}{*}{44320} & \multirow[t]{4}{*}{29} & 7.58 & SHNT & 4.595 & 6.456 & 4.158 & 3.662 \\
\hline & & 1.493 & $\mathrm{BR}$ & 1.009 & 1.183 & 1.092 & 0.851 \\
\hline & & 102 & Pettitt & 84 & 68 & 80 & 42 \\
\hline & & 1.408 & VNR & $2.258^{*}$ & $1.708^{*}$ & $2.255^{*}$ & $2.281^{*}$ \\
\hline \multirow[t]{4}{*}{45253} & \multirow[t]{4}{*}{29} & 7.58 & SHNT & 3.414 & 1.657 & 6.757 & 2.496 \\
\hline & & 1.493 & $\mathrm{BR}$ & 1.054 & 1.076 & 1.202 & 1.313 \\
\hline & & 102 & Pettitt & 62 & 50 & 100 & 58 \\
\hline & & 1.408 & VNR & $1.608^{*}$ & $2.112^{*}$ & $1.927^{*}$ & $1.983^{*}$ \\
\hline 45254 & 29 & 7.58 & SHNT & 4.532 & 3.123 & 2.85 & 2.048 \\
\hline & & 1.493 & $\mathrm{BR}$ & 1.141 & 1.337 & 1.186 & 0.92 \\
\hline & & 102 & Pettitt & 62 & 76 & 64 & 80 \\
\hline & & 1.408 & VNR & $1.7^{*}$ & $1.658^{*}$ & $1.84^{*}$ & $2.126^{*}$ \\
\hline
\end{tabular}

Note: Stations 2917001 and 44255 did not pass the homogeneity tests for monthly series while station 2917001 did not pass the homogeneity tests for seasonal series also. Therefore, they are eliminated from further analyses.

${ }^{*}$ Significant at $\alpha=0.05$. 
whether the error is an overestimate or underestimate.

$$
\operatorname{MAD}=\frac{\sum_{t=1}^{n}\left|Y_{t}-\hat{Y}_{t}\right|}{n} .
$$

\subsubsection{Pearson's correlation coefficient}

Pearson's correlation coefficient is a popular measure of the linear correlation between two variables. The value $r$ lies between -1 and 1 (inclusive), where -1 represents total negative correlation between the two variables, 0 represents no correlation, and 1 is total positive correlation.

$$
r=\frac{\sum_{i=1}^{n}\left(x_{i}-\bar{x}\right)\left(y_{i}-\bar{y}\right)}{\sqrt{\sum_{i=1}^{n}\left(x_{i}-\bar{x}\right)^{2}} \sqrt{\sum_{i=1}^{n}\left(y_{i}-\bar{y}\right)^{2}}},
$$

where $x_{i}$ represents the observed value at time $i, y_{i}$ represents the forecasted value at time $i$, and $\bar{x}$ and $\bar{y}$ are the mean observed value and mean forecasted value, respectively.

\section{Results and discussion}

\subsection{Homogeneity of rainfall series}

From the result of homogeneity test for monthly rainfall series, 15 out of 20 monthly rainfall series were homogeneous at $95 \%$ significance level, as shown in table 4. Out of the five remaining, four were found to be 'suspect'. There was only one categorized as 'doubtful'. 'Suspect' or 'doubtful' monthly rainfall series were found at stations 2917001 and 44255, regardless testing on annual median or annual maximum rainfall. This result suggested that rainfall series for these two stations might not be suitable for further analysis.

For seasonal rainfall series, 15 series were found under 'useful' category. However, four 'suspect' or 'doubtful' series were found when testing on annual median. All except one seasonal rainfall series were 'useful' when annual maximum was used as testing variable. Similar to monthly rainfall series analysis, seasonal rainfall series at station 2917001 was 'doubtful'.

\subsection{Model performance}

Goodness-of-fit of the generated model was measured by MAD, MSE and MAPE. There is no any criterion to indicate whether the model is good or bad for MAD and MSE. However, value of MAPE can be interpreted according to table 3, as shown in previous part. The results of MAD, MSE and MAPE for the whole study period are shown in table 5.

The MAD of monthly rainfall series ranged from 64.2 to 84.8 , indicating that the forecasted monthly rainfall had a deviation of $64.2-84.8 \mathrm{~mm}$ rainfall. For instance, the forecasted rainfall at station 44320 was, on average, more or less $84.8 \mathrm{~mm}$ rainfall every month, while average monthly rainfall was $215 \mathrm{~mm}$. Figure 2 shows the boxplot of monthly rainfall series over the 29 years at station 44320 and the curve shows average monthly rainfall.

Table 5. Values of average rainfall, MAD, MSE, MAPE and $r$ of monthly and seasonal analyses at each station for the whole period (up to 2012).

\begin{tabular}{llcrrrr}
\hline \multirow{2}{*}{ Stations code } & & Average & MAD & \multicolumn{1}{c}{ MSE } & MAPE & $r$ \\
\hline \multirow{2}{*}{44239} & Monthly & 170.9 & 65.5 & 6955.8 & 0.68 & 0.38 \\
& Seasonal & 509.7 & 119.3 & 23591.5 & 0.35 & 0.61 \\
\multirow{2}{*}{44255} & Monthly & 160.7 & 68.6 & 7964.3 & 1.04 & 0.42 \\
& Seasonal & 476.8 & 133.8 & 27587.0 & 0.32 & 0.64 \\
\multirow{2}{*}{44320} & Monthly & 170.7 & 72.4 & 9478.6 & 0.78 & 0.47 \\
& Seasonal & 511.3 & 141.2 & 39189.8 & 0.30 & 0.66 \\
\multirow{2}{*}{45253} & Monthly & 215.0 & 84.8 & 10621.4 & 0.75 & 0.42 \\
\multirow{2}{*}{45254} & Seasonal & 640.8 & 161.8 & 42235.9 & 0.29 & 0.48 \\
& Monthly & 174.3 & 76.2 & 9665.6 & 0.77 & 0.31 \\
\multirow{2}{*}{2815001} & Seasonal & 517.0 & 152.0 & 34403.6 & 0.35 & 0.50 \\
\multirow{2}{*}{2818110} & Monthly & 180.7 & 79.4 & 10314.9 & 0.87 & 0.42 \\
\multirow{2}{*}{2913001} & Seasonal & 536.5 & 154.3 & 42869.4 & 0.31 & 0.53 \\
& Monthly & 147.7 & 66.6 & 7323.3 & 1.14 & 0.33 \\
& Seasonal & 440.8 & 142.5 & 34206.2 & 0.48 & 0.53 \\
& Monthly & 162.5 & 64.2 & 6918.4 & 0.88 & 0.50 \\
& Seasonal & 485.8 & 133.5 & 28138.6 & 0.34 & 0.44 \\
& Monthly & 160.0 & 70.7 & 8810.3 & 1.82 & 0.38 \\
& Seasonal & 475.6 & 133.5 & 29556.5 & 4.07 & 0.64 \\
\hline
\end{tabular}




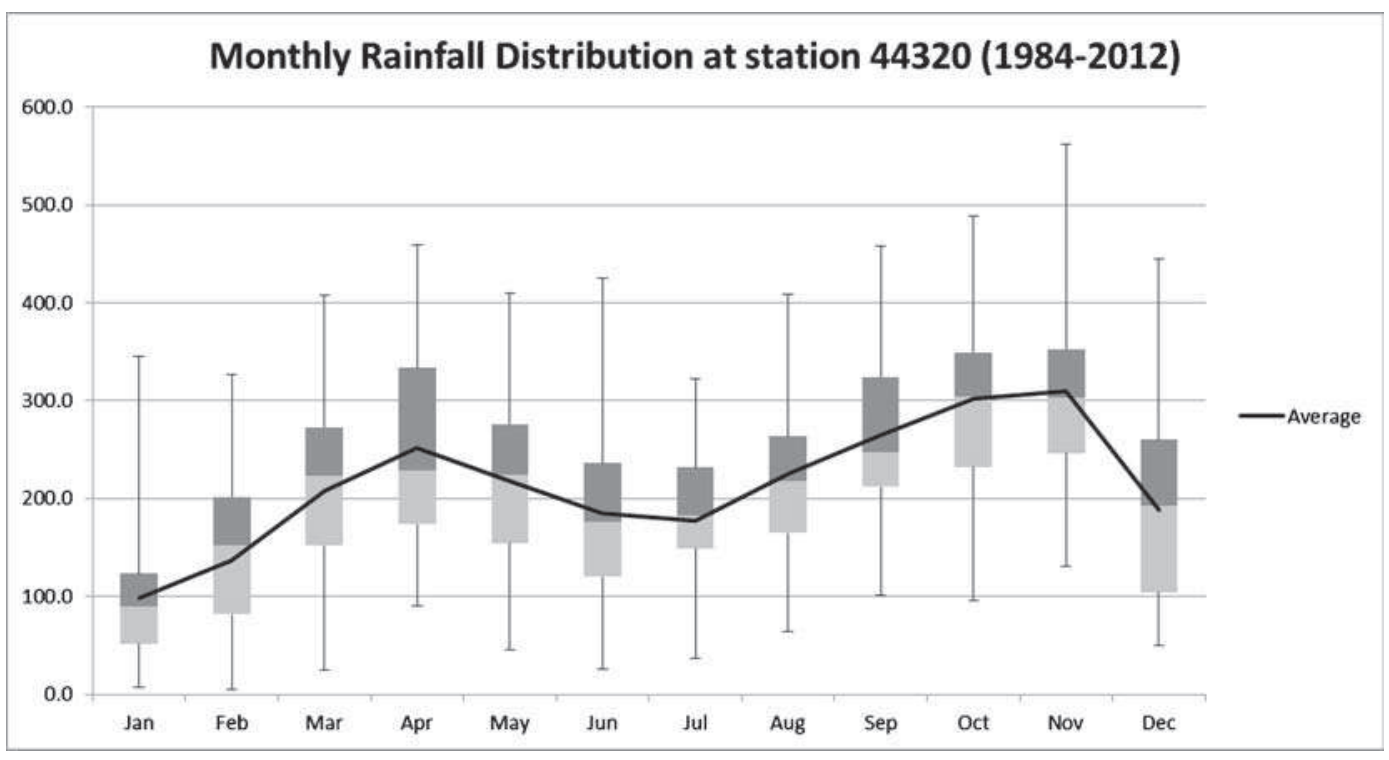

Figure 2. Boxplot of monthly rainfall at station 44320 .

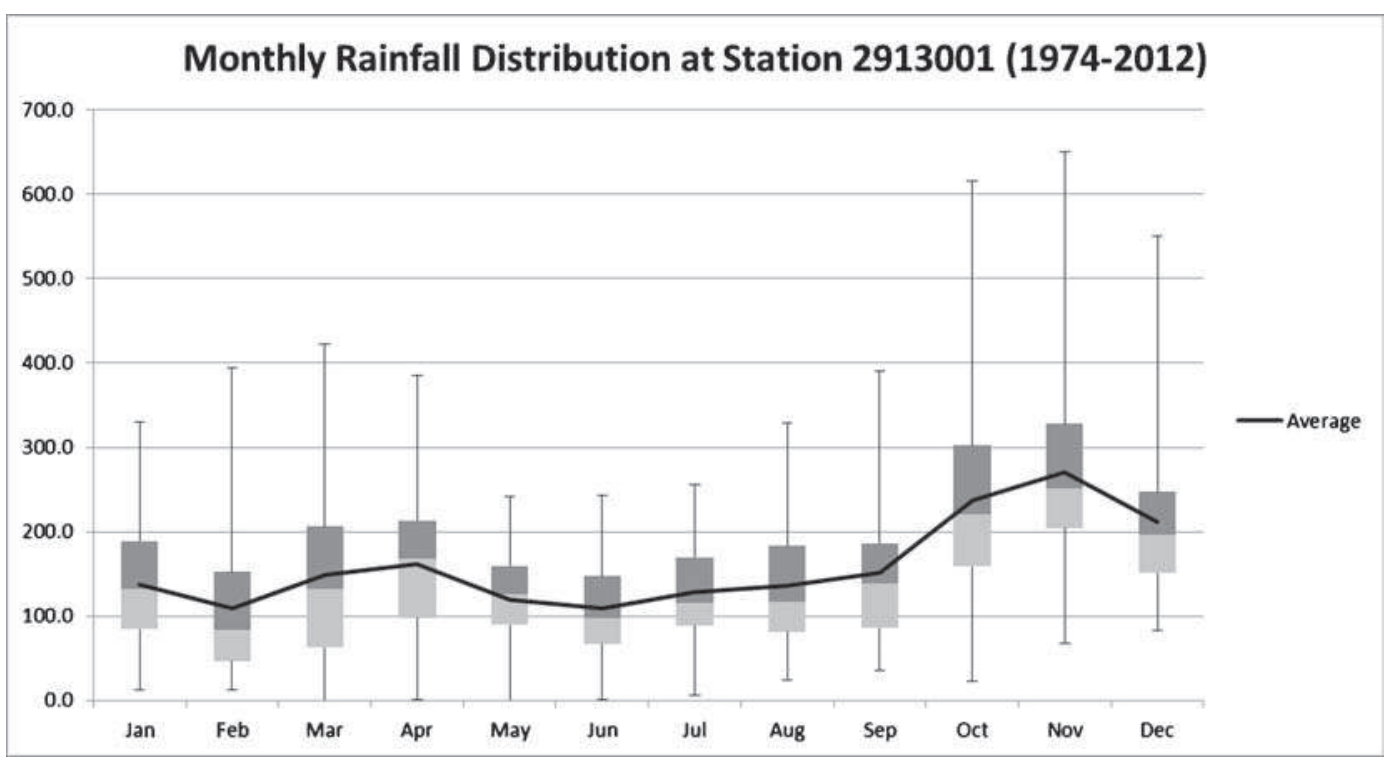

Figure 3. Boxplot of monthly rainfall at station 2913001.

For seasonal rainfall series, the value of MAD was found in the interval between 119.3 and $161.8 \mathrm{~mm}$. The MAD of forecasted seasonal rainfall was 161.8 $\mathrm{mm}$ at station 44320 which has an average seasonal rainfall of $640.8 \mathrm{~mm}$. For monthly rainfall series, the MAD value is $39.44 \%$ of the average rainfall at station 44320 , while the percentage decreased to $25.25 \%$ for seasonal rainfall series. Every station showed the same situation. Therefore, it was concluded that the model of seasonal rainfall was better than the monthly rainfall model when MAD was used as the indicator of goodness-of-fit of the model.

As mentioned above, due to the squared error term, the MSE will accentuate when the error is large. Thus, the value of MSE is generally larger than MAD value. For this study, minimum MSE was used to optimize smoothing parameters of Holt-Winters method for each station. The values of MSE for the monthly rainfall series were large, which lay between 6918.4 and 10621.4. As for seasonal rainfall series, the values ranged from 23591.5 to 42869.4 .

Compared to MSE, MAPE would be a better indicator of goodness-of-fit since it does not magnify when the errors are large. However, there are some drawbacks of this indicator. Firstly, when the actual is zero, the denominator becomes zero, which is known as 'undefined'. Next, if the actual is less than 1, the value of MAPE would become 


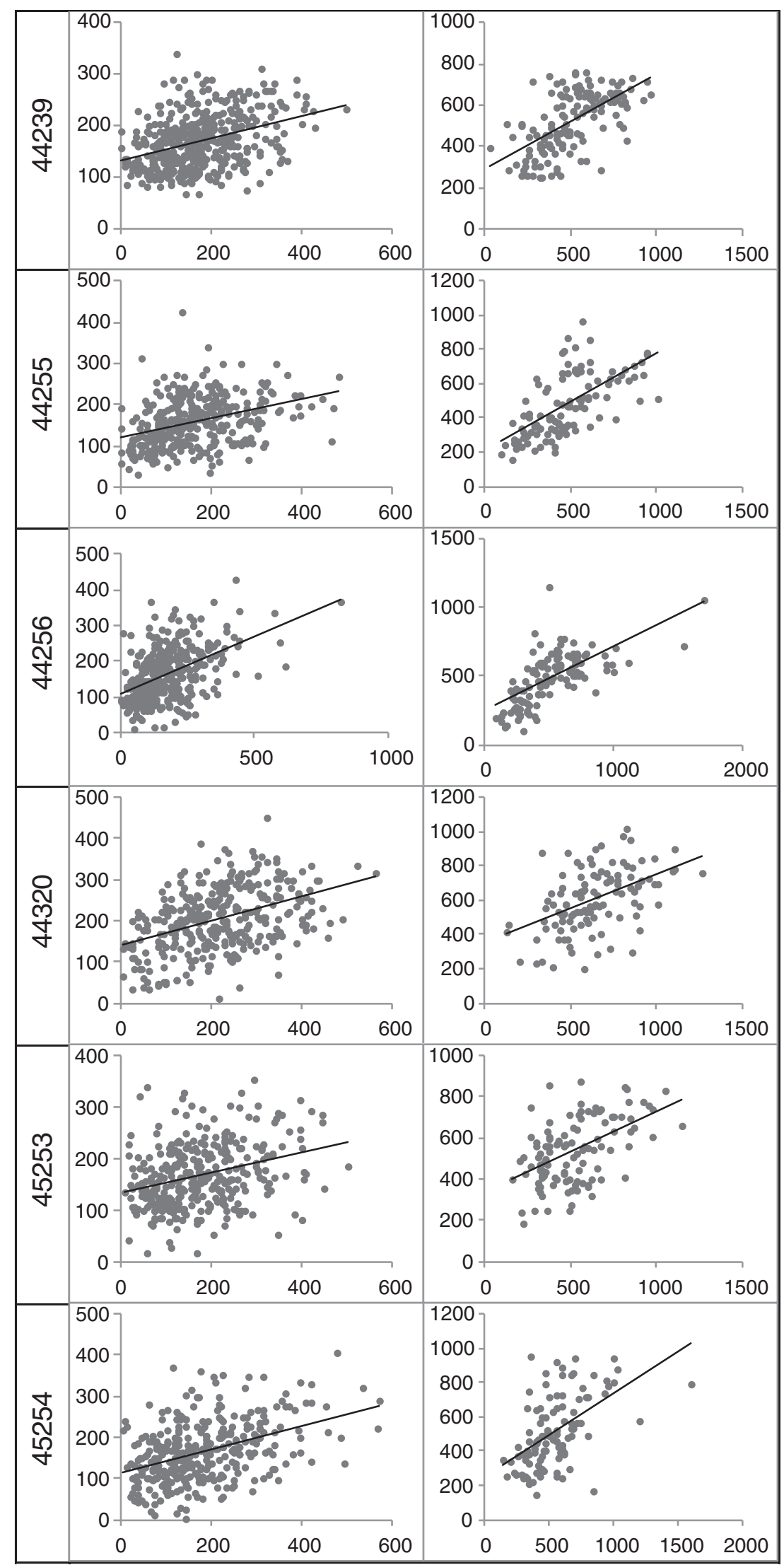

Figure 4. Correlation between observed values and forecasted values of monthly (left) and seasonal (right) rainfalls for each station. 


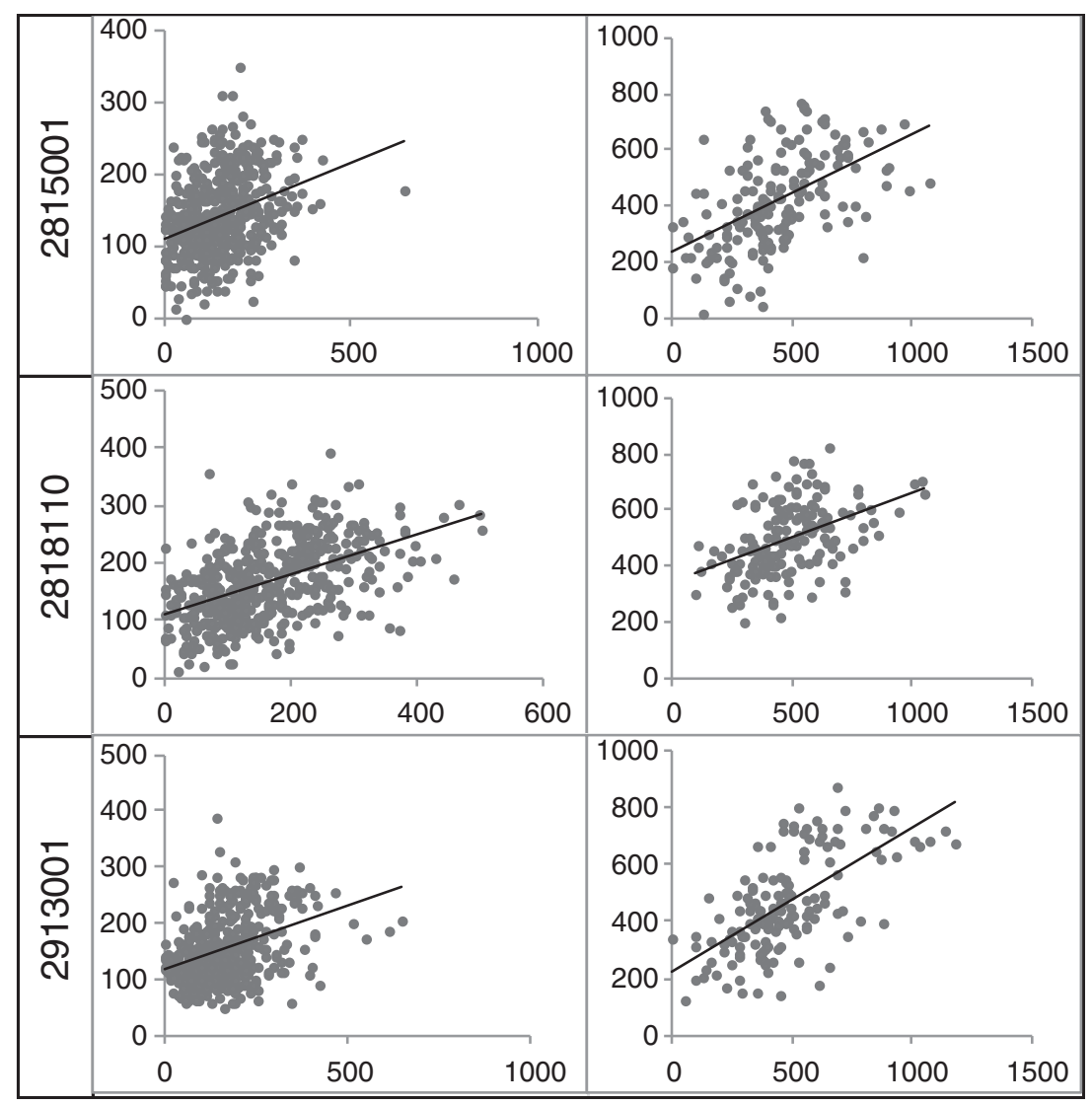

Figure 4. (Continued.)

large. The values of MAPE found in this study were compared to the scale of judgment developed by Lewis (1982). MAPEs shown in monthly series were unsatisfactory with the values from $64.93 \%$ to $182.25 \%$, and these values are categorized as 'inaccurate forecast'.

On the other hand, seasonal rainfall series presented a better result when most of the MAPE fell in the range $29.15 \%-47.57 \%$. All values in the interval of $21 \%-50 \%$ are 'reasonable forecast'. However, station 2913001 showed $182.25 \%$ in monthly analysis and $406.53 \%$ in seasonal analysis. Referring to the boxplot of rainfall distribution at station 2913001 (figure 3), there were few months with very less rainfall (close to zero) and the range of the monthly rainfall was wide (the minimum and maximum rainfall in October were 23 and $615.5 \mathrm{~mm}$ ). For seasonal rainfall series, a special case of seasonal rainfall with $0.6 \mathrm{~mm}$ caused the uncommonly large MAPE. With exception of station 2913001, forecasted seasonal rainfall series was a better model as compared to monthly rainfall series.

The correlation coefficient, $r$, measured the strength and the direction of the linear relationship between the observed values and forecasted values. Scatter plots (figure 4 ) of the observed values and forecasted values of monthly and seasonal rainfall of each station were plotted. As shown in table 5, all $r$ values are found to be positive, which indicates that the observed values and forecasted values are positively correlated for all series. Generally, the linear relationship of seasonal rainfall series is stronger than that of monthly rainfall series which is consistent with the results found from the three tests.

\subsection{Trend analysis}

Trends of monthly and seasonal rainfall series at each station were plotted to show the changes in rainfall pattern for the study period. Station 2913001 , which is located in the western region of the study area, is the nearest station to the west coast. As shown in figure 5(a), rainfall at this station was generally increasing but decreased during the period of April 2001-April 2005. From seasonal analysis, the rainfall trend was also increasing but with more fluctuations. Similar to monthly analysis, rainfall decreased from ITM2 2001 to ITM1 2005.

Stations 2815001, 44255 and 44256 are nearby stations, which are also located in western region. Station 2815001 has the longest rainfall data with 43 years among all 9 stations. Both monthly and 


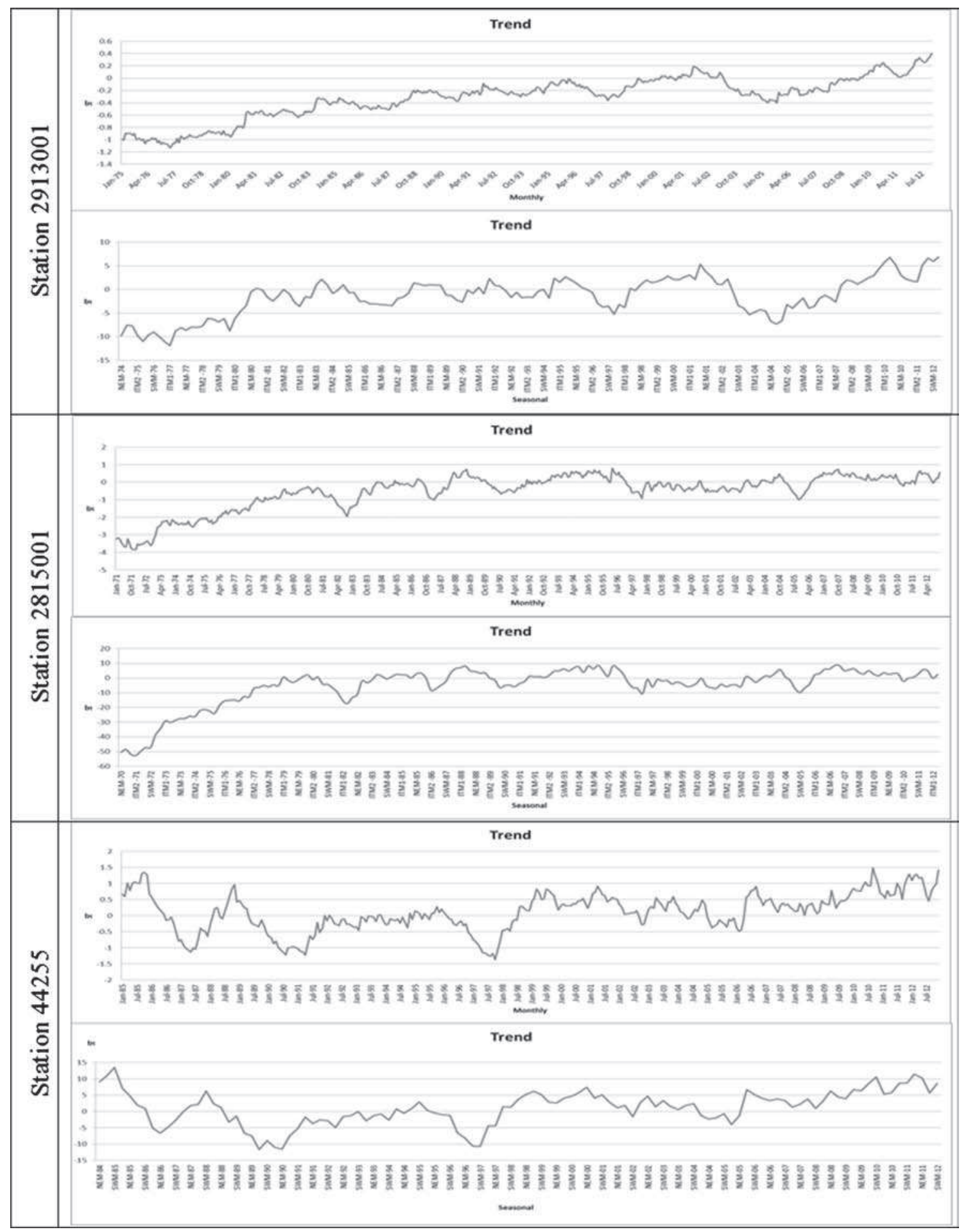

Figure 5. Trend plots of monthly and seasonal rainfalls at each station.

seasonal analyses get the same result (figure 5a); an increasing rainfall trend was shown from 1971 to mid of 1996 and remained consistent with a turning point in September 2005. Stations 44255 and 44256, situated next to station 2815001, have a shorter period of data (29 and 32 years, respectively). As shown in figure 5(a), rises and falls of rainfall can be found at stations 44255 during the earlier period and increasing rainfall trend was shown from August 1997. However, rainfall decreased during the earlier period in seasonal analysis but increased thereafter. During the whole study period, increasing rainfall trend was revealed at station 44256 in both monthly and seasonal 


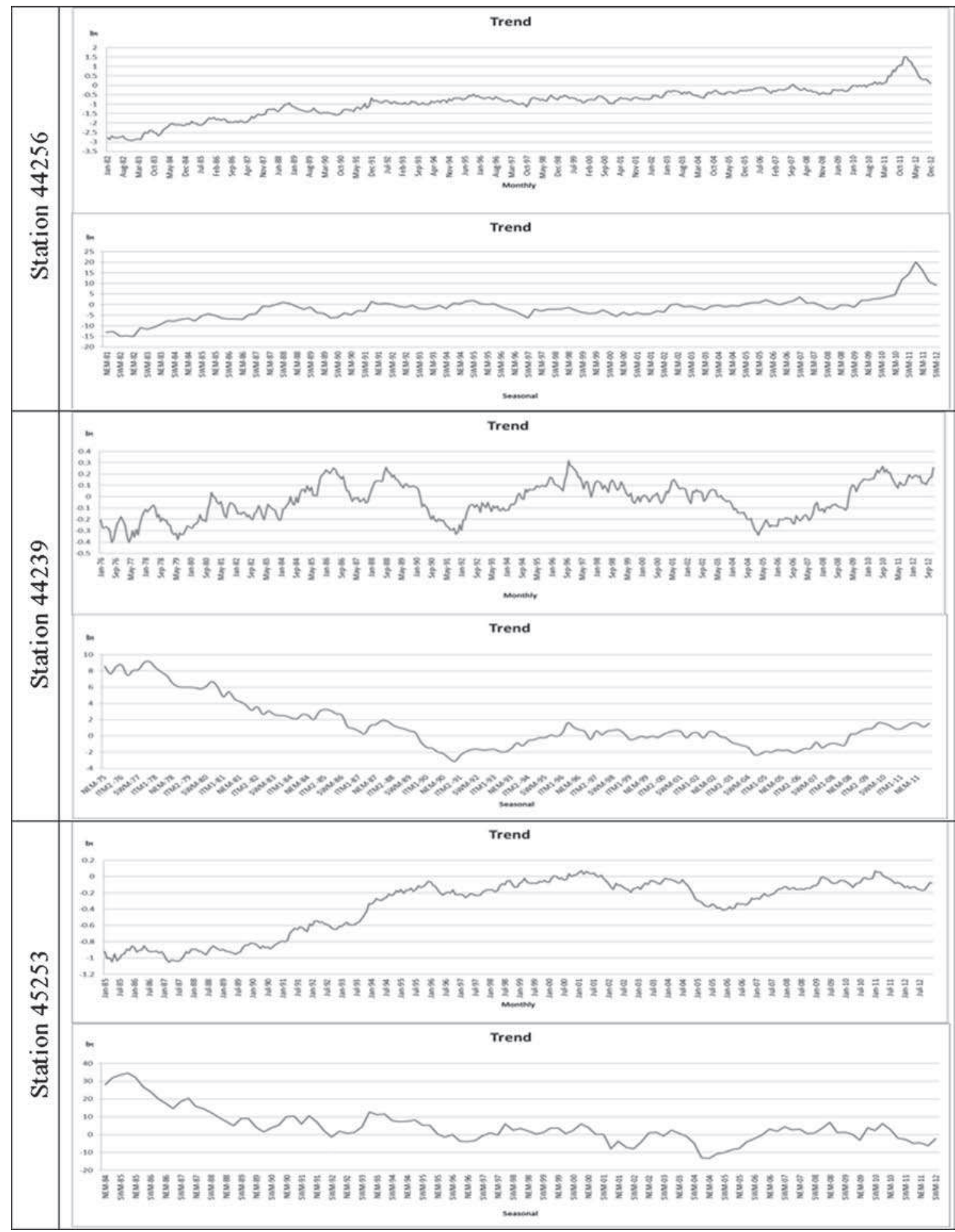

Figure 5. (Continued.)

analysis, as shown in figure 5(b). Comparing results from these three nearby stations in the overlapped period, it was revealed that similar results were shown at stations 2815001 and 44255 but not at station 44256.

Station 44239 represents the southern part of the study area. As shown in figure 5(b), there were two turning points in the rainfall trend; monthly rainfall increased from 1975 to 1988 and hit 2 minima point in October 1991 and March 2005, after that increasing trend was shown. Instead of increasing, seasonal analysis discovered decreasing trend from 1975 to SWM 1991 and turned into slightly increasing trend until 2012.

There are two stations located in the southeastern region, namely stations 45253 and 45254 . 
During the whole study period, monthly rainfall at station 45253 exhibited a generally increasing trend (figure 5b). However, result from seasonal analysis showed a downward trend. Figure 5(c) shows the increasing trend in both monthly and seasonal analysis at station 45254 for the whole study period.

For station 2818110 that represents the eastern region in the study area, similar results were found in monthly and seasonal analyses (figure $5 \mathrm{c}$ ), which showed steep decreasing trend during the period of 1972-1977 and remained consistent afterwards.

The only station located in the northeastern region is station 44320. As shown in figure 5(c), rainfall pattern in seasonal analysis was similar with the result from monthly analysis but in a 'smoother' form. Increasing trend was found during the whole study period but was more obvious in the earlier period, 1984-1993.

One of the benefits of modelling rainfall using additive Holt-Winters method is that the graph plotted using the estimated trend shows the movement throughout the entire study period. From the figure shown, it was noticed that rainfall trend tend to increase at most stations from year 2005 . Such observation is important for future forecasting. Rainfall in the Langat River Basin is more likely to increase in recent years. Flood prevention should be strengthened in this area.

\subsection{Accuracy of model forecasting}

In order to test the accuracy of rainfall series forecasting using Holt-Winters model, rainfall data of

Table 6. Values of MAD, MSE and MAPE of monthly and seasonal forecast for years 2010-2012 at each station.

\begin{tabular}{|c|c|c|c|c|}
\hline \multicolumn{2}{|c|}{ Stations code } & \multirow{2}{*}{$\frac{\text { MAD }}{54.20}$} & \multirow{2}{*}{$\begin{array}{c}\text { MSE } \\
4499.05\end{array}$} & \multirow{2}{*}{$\frac{\text { MAPE }}{0.49}$} \\
\hline 44239 & Monthly & & & \\
\hline & Seasonal & 86.60 & 10499.3 & 0.17 \\
\hline \multirow[t]{2}{*}{44255} & Monthly & 85.90 & 11117.3 & 0.53 \\
\hline & Seasonal & 145.47 & 28890.5 & 0.22 \\
\hline \multirow[t]{2}{*}{44256} & Monthly & 125.97 & 32964 & 0.69 \\
\hline & Seasonal & 367.59 & 254160 & 0.39 \\
\hline \multirow[t]{2}{*}{44320} & Monthly & 86.27 & 11238.5 & 0.37 \\
\hline & Seasonal & 140.71 & 31852.7 & 0.20 \\
\hline \multirow[t]{2}{*}{45253} & Monthly & 66.76 & 7699.61 & 0.59 \\
\hline & Seasonal & 157.51 & 31507.5 & 0.37 \\
\hline \multirow[t]{2}{*}{45254} & Monthly & 77.82 & 9442.85 & 0.53 \\
\hline & Seasonal & 179.20 & 63522.4 & 0.25 \\
\hline \multirow[t]{2}{*}{2815001} & Monthly & 72.33 & 7500.65 & 0.77 \\
\hline & Seasonal & 110.75 & 19483.6 & 0.24 \\
\hline \multirow[t]{2}{*}{2818110} & Monthly & 72.10 & 7999.34 & 0.48 \\
\hline & Seasonal & 157.31 & 34154.8 & 0.30 \\
\hline \multirow[t]{2}{*}{2913001} & Monthly & 81.45 & 10320.2 & 0.67 \\
\hline & Seasonal & 150.89 & 33489.9 & 0.25 \\
\hline
\end{tabular}

Note: Station 44256 had received extraordinarily more rainfall in year 2011 which makes the value of MAD, MSE and MAPE large. years 2010-2012 was excluded from the rainfall series and was used in model verification. Comparison of forecasted data and recorded data was then performed using MAD, MSE and MAPE to measure the accuracy and efficiency of Holt-Winters method in rainfall series forecasting. Results of the comparison are presented in table 6 .

Most of the errors of forecasts were acceptable. A noteworthy result was discovered at station 44256 . All values of MAD, MSE and MAPE were large in both monthly and seasonal forecasts. It was found that this station received a lot of rainfall during year 2011, monthly rainfall of more than $400 \mathrm{~mm}$ was discovered in 6 months and maximum monthly rainfall was $822.3 \mathrm{~mm}$ during the year. The average annual rainfall at this station was $2047.9 \mathrm{~mm}$, while the annual rainfall of year 2011 hit $4558.6 \mathrm{~mm}$, which is twice of the average annual rainfall. Thus, the inaccuracy of forecasting was caused by the abnormal wet year.

\section{Conclusions}

In this study, both monthly and seasonal rainfall series were modelled and the underlying trend was tracked using the additive Holt-Winters method at the nine stations in Langat River Basin. Instead of getting a single direction trend, increasing or decreasing, the rainfall series was modelled to track the fluctuations during the study period.

Rainfall data with more than 25 years and less than $10 \%$ missing data were obtained at 10 stations. However, only nine stations are homogeneous. The rainfall models were first checked for the model performance using four measurements, namely MAD, MSE, MAPE and correlation coefficient. It was found that the accuracy of the seasonal rainfall models were generally better than the monthly rainfall models.

Most of the stations exhibited similar result in monthly and seasonal analyses. Generally, increasing trends over the whole study period were shown at stations 2913001, 2815001 and 44256 in the western region except station 44255 . Results from station 44255 revealed more fluctuation during the study period. However, different results were discovered in monthly and seasonal analyses at station 44239 in the southern region. Fluctuations were shown in the monthly analysis, while a generally decreasing trend was found in the seasonal analysis.

In the southeastern region, both monthly and seasonal analyses at station 45254 and monthly analysis at station 45253 exhibited upward trend. However, downward trend was found in the seasonal analysis at station 45253. Station 2818110 in the eastern region showed result of decreasing trend in both monthly and seasonal analyses. Increasing 
trends in monthly and seasonal analyses were found at the only station in north-eastern region, which is station 44320 .

The accuracy of forecasting using additive HoltWinters method was also tested using MAD, MSE and MAPE. Most of the forecasts were acceptable except at station 44256 due to the abnormal wet year in 2011.

From the result of trend analysis at the three nearby stations 2815001, 44255 and 442564 in western region, it was noticed that the movement of trend depends on the length of the study period. Thus, data with longer period should be used in order to get a more comprehensive picture of rainfall pattern. In addition, further investigations are required for those stations, which exhibited no rainfall trend but fluctuations with large magnitude were found. Instead of rainfall amount, trends of rainfall intensity and number of wet days should also be investigated for climate change assessment. Understanding rainfall patterns is very important for forecasting future rainfall, which can be used for water resources planning and flood protection.

\section{References}

Afzal M, Mansell M G and Gagnon A S 2011 Trends and variability in daily precipitation in Scotland; Procedia Environ. Sci. 6 15-26.

Caloiero T, Coscarelli R, Ferrari E and Mancini M 2011 Trend detection of annual and seasonal rainfall in Calabria (southern Italy); Int. J. Climatol. 31 44-56.

Chang H and Kwon W 2007 Spatial variations of summer precipitation trends in South Korea, 1973-2005; Environ. Res. Lett. 2045012.

Criss R E and Winston W E 2008 Do Nash values have value? Discussion and alternate proposals; Hydrol. Process. 22 2723-2725.

Ghahraman B and Taghvaeian S 2008 Investigation of annual rainfall trends in Iran; J. Agr. Sci. Technol. 10 93-97.

Guhathakurta P and Rajeevan M 2008 Trends in the rainfall pattern over India; Int. J. Climatol. 28 14531469.

Gundalia M J and Dholakia M B 2012 Prediction of maximum/minimum temperatures using Holt Winters method with Excel spreadsheet for Junagadh region; Int. J. Eng. Res. Technol. 1.
Holt C C 2004 Forecasting seasonals and trends by exponentially weighted moving averages; Int. J. Forecasting 20 $5-10$.

Jayawardene H K W I, Sonnadara D U J and Jayewardene D R 2005 Trends in rainfall in Sri Lanka over the last century; Sri Lankan J. Phys. 6 7-17.

Kamruzzaman M, Beecham S and Metcalfe A V 2011 Nonstationarity in rainfall and temperature in the Murray Darling Basin; Hydrol. Process. 25 1659-1675.

Karpozos D K, Kavalieratou S and Babajimopoulos C 2010 Trend analysis of precipitation data in Pieria region (Greece); European Water 30 31-40.

Krause P, Boyle D P and Bäse F 2005 Comparison of different efficiency criteria for hydrological model assessment; Adv. Geosci. 5 89-97.

Lewis C D 1982 Industrial and business forecasting methods: A practical guide to exponential smoothing and curve fitting; Butterworth Scientific, 143p.

Luís M D, Raventós J, González-Hidalgo J C, Sánchez J R and Cortina J 2000 Spatial analysis of rainfall trends in the region of Valencia (east Spain); Int. J. Climatol. 20 1451-1469.

Miller W P and Piechota T C 2008 Regional analysis of trend and step changes observed in hydroclimatic variables around the Colorado River basin; J. Hydrometeorol. 9 1020-1034.

Mondal A, Kundu S and Mukhopadhyay A 2012 Rainfall trend analysis by Mann-Kendall test: A case study of northeastern part of Cuttack district, Orissa; Int. J. Geol. Earth Environ. Sci. 2 70-78.

Obot N I, Chendo M A C, Udo S O and Ewona I O 2010 Evaluation of rainfall trends in Nigeria for 30 years (19782007); Int. J. Phys. Sci. 5 2217-2222.

Schaefli B and Gupta H V 2007 Do Nash values have value? Hydrol. Process. 21 2075-2080.

Seleshi Y and Zanke U 2004 Recent changes in rainfall and rainy days in Ethiopia; Int. J. Climatol. 24 973-983.

Sopipan N 2014 Forecasting rainfall in Thailand: A case study of Nakhon Ratchasima Province; Int. J. Environ. Ecol. Geol. Geophys. Eng. 8 717-721.

Tabari H, Abghari H and Talaee P H 2012 Temporal trends and spatial characteristics of drought and rainfall in arid and semi-arid regions of Iran; Hydrol. Process. 26 33513361.

Wang S, Zhang X, Liu Z and Wang D 2013 Trend analysis of precipitation in the Jinsha River Basin in China; J. Hydrometeorol. 14 290-303.

Wijingaard J B, Klein Tank A M G and Können G P 2003 Homogeneity of 20th century European daily temperature and precipitation series; Int. J. Climatol. 23 679-692.

Winters P R 1960 Forecasting sales by exponentially weighted moving averages; Manag. Sci. 6 324-342.

Wong C L, Venneker R, Uhlenbrook S, Jamil A B M and Zhou Y 2009 Variability of rainfall in Peninsular Malaysia; Hydrol. Earth Syst. Sci. Discuss. 6 6571-5503. 